\title{
Der Flüchtling
}

(aus Die Reise, Roman in Kurzgeschichten)

\section{Adolf Jens Koemeda}

Dr. med., Psychiater und Schriftsteller, Mitglied FMH

Lange überlegte ich mir, Herr Doktor, ob ich die folgenden Seiten in meinen Brief an Sie aufnehmen sollte. Ich entschied nein und schrieb gleich weiter. Dann las ich aber den Text noch einmal und fragte mich: Auslassen, warum eigentlich? Diese Probleme, diese Sorgen, ja, diese Nöte gehören doch zum Alltag der meisten Migranten, das Kapitel sollte keineswegs gestrichen werden.

Sie sieht so aus: relativ gross, etwa ein Meter fünfundsiebzig, nicht ausgesprochen dick, eher fest, stattlich, ja, eine kraftvolle weibliche Statur. Grosser Busen, aber straff; dasselbe kann man von ihrem Hinterteil sagen. Auffallend schmale Hände, Fingernägel unlackiert; eine kleine Stupsnase mit ein paar Sommersprossen;

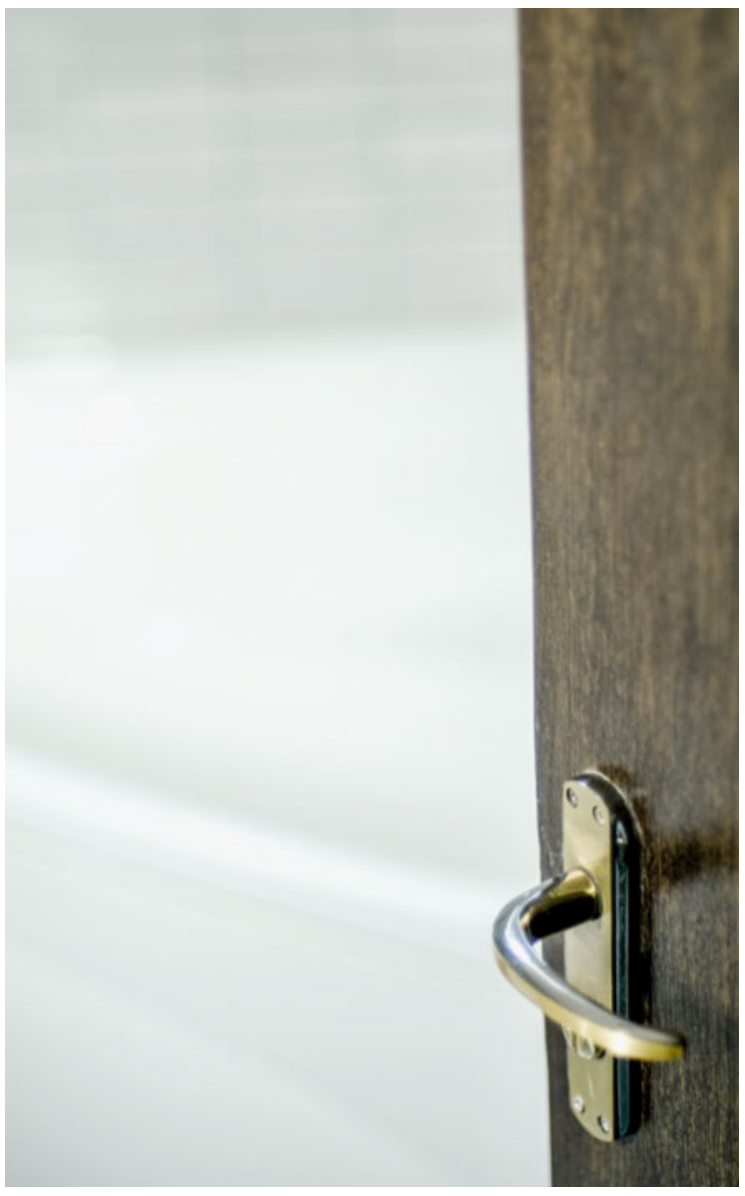

blondes Haar, sicher nicht ganz ohne chemische Unterstützung Und das Alter? Schwer zu schätzen. Vierzig, fünfundvierzig? Ungefähr wie meine Mutter. Eben! Für mich eine äusserst irritierende Tatsache.

In der Wohnung gab es ein gemeinsames Badezimmer, also kein abgetrenntes Gästeklo oder eine Extradusche. Eines Abends betrat ich das Bad - nichtsahnend, Herr Doktor, das können Sie mir wirklich glauben -, die Tür war ja offen. Hannelore lag in der Badewanne, nur der Kopf und der Busen ragten aus den Schaumhügeln heraus.

- Entschuldigung, sagte ich leise und verliess schnell den Raum.

Ja, schnell. Vielleicht zu schnell. Das Bad war doch nicht abgeschlossen ... ein Zufall? Möglicherweise. Mit Sicherheit konnte ich mir aber diese Frage nicht beantworten. Ich wartete vor der Tür, zwei Minuten, drei, wahrscheinlich noch länger. Dann klopfte ich; kurz und sehr leise, und trat ein. Hannelore stand schon auf dem hellblauen Vorleger, ein Bein auf dem Rand der Wanne - sie trocknete gerade ihren Oberschenkel.

- Sorry! Ich muss schnell meine Nagelschere holen, murmelte ich.

- Kein Problem. Wenn du gerade da bist, Simmi ... könntest du mir bitte den Rücken abtrocknen? - Gerne!

Ich tat es langsam, zögernd, ohne Druck ... lange. Und dann: Sie drehte sich plötzlich um. Mit irgendeiner Aktion hatte ich gerechnet - hatte das alles ja durch mein Zurückkommen provoziert -, als Hanni aber so vor mir stand, war ich doch überrascht. Ihr Busen war viel mächtiger, als mir vorher erschienen war; nicht ausgesprochen himmelwärts strebend - das war bei diesem Volumen einfach nicht machbar -, und trotzdem sehr in Ordnung.

Ich rührte mich nicht.

- Na?, fragte sie. - Trocknest du nicht weiter? Oder hast du noch nie eine nasse (ja, sie sagte nasse, nicht nackte) Frau gesehen?

- Wie ich mich - jetzt schon matt - erinnere, ja. Aber ... - Was aber? Ich friere, trockne mich bitte ab.

Das tat ich also: Schulter, Oberarme ... sehr gründlich. 
Den Hals auch, noch tiefer wollte ich allerdings nicht gehen. Ich stockte.

- Ich friere.

- Ich nicht.

Eine idiotische Bemerkung ... in diesem Augenblick fiel mir nichts Gescheiteres ein. (Obwohl, dachte ich ein paar Stunden später, vielleicht war sie gar nicht so idiotisch; man kann es auch positiv deuten: Mir war heiss geworden.)

Sie nahm mir das blassgelbe Badetuch aus der Hand und warf es auf das Waschbecken. Dann packte sie mich sanft und drückte mich an sich. Mein Kopf landete zwischen ihren Brüsten.

- Ich friere immer noch.

Sie nahm meine rechte Hand und legte sie auf ihren linken Busen. Meine Finger berührten vorsichtig ihre Brustwarze. Sie war steif.

- Ja, Hanni, ich merke es.

Sie drückte meinen Kopf etwas stärker gegen ihr Brustbein. Meine freie Hand griff nach ihrer rechten Brust. Ich hielt jetzt die beiden nach Jasminseife riechenden Wölbungen fest, ich klammerte mich an sie wie ein Säugling.

Lange standen wir aber nicht so, zehn, höchstens zwanzig Sekunden.

Und dann?

Dann kam das unrühmliche Ende. Ich küsste Hannelore am Hals, an ihrer rechten Brust, die mir als erste angeboten wurde, und ... liess meine Hände fallen. Sie schaute überrascht zu mir hinunter und schüttelte ein wenig den Kopf - sie lächelte und fragte: - Was hast du, Simmi?

Keine Antwort. Ich war schon unterwegs und hielt in der nächsten Sekunde die Klinke in der Hand. Ja, ich verschwand in meinem Zimmer.

Dutzende von Bildern zogen mir im Bett durch den Kopf. Attula, zwei Kameradinnen aus ihrer Musikgruppe, aber auch meine Schwester Martha, meine Mutter, unsere Mathe-Lehrerin und sogar meine muslimische Grossmutter ... lauter Frauen. Erregt war ich in dem Augenblick nicht, nicht mehr.

Das veränderte sich allerdings bald, aber nur für kurze Zeit. Neue Bilder stellten sich ein und vor allem neue Gedanken.

Du hast Hanni beleidigt, enttäuscht ... ja, verletzt an einem sehr empfindlichen Punkt. Warum? Sie hat dich aufgenommen, sie macht viel für dich; von Anfang an! Das hat sie nicht verdient. Von keinem Mann ... von dir am allerwenigsten.

Und was jetzt? ... Ja, das war meine erste Frage. Ist alles verloren, vorbei. Oder doch nicht alles? Was könnte ich in dem Moment noch tun?
Ich stand auf und ging hinaus in den dunklen Eingangsraum. Die Tür zum Badezimmer war nur angelehnt, darin kein Licht. Dafür aber daneben, in Hannelores Schlafzimmer; der kleine Lichtstreifen unter der Tür verriet sie. Ich kam näher, ganz leise, ich horchte. Es gab nur merkwürdige, kaum hörbare Geräusche ... Seufzte sie? Oder war es ein Schluchzen?

Ich stand lange vor ihrem Zimmer, sicher länger als fünf Minuten. Langsam begann ich zu frieren. Soll ich jetzt klopfen, fragte ich mich. Oder gleich eintreten? Oder doch lieber in mein Bett zurückkehren? Hin und her. Gleich wie in den letzten Tagen vor meiner Abreise von Foča: unschlüssig, zögernd, kaum handlungsfähig ... Na ja, dieser Zug von mir überraschte mich nicht, den kannte ich. Und trotzdem! Obwohl da nichts Unbewusstes im Spiel war - da hätte sich der alte Freud sicher geärgert -, konnte ich es nicht ändern. Zuletzt aber doch. Ich klopfte.

Das Licht unter der Türspalte ging sofort aus. Erst nach einer Weile: - Ja ... herein!

Ich trat ein. - Ich friere ... Diese zwei Wörter sagte ich sehr leise.

Hanni: - Ich auch.

Sie schlug die Bettdecke auf. Ich machte zwei, drei Schritte und blieb wieder stehen. Und weiter? Wie vorher: hin und her.

Sie: - Na? Zu zweit friert man weniger.

Noch ein paar Sekunden, dann schlüpfte ich zu ihr unter die Decke. Eine Weile lagen wir still, auf einmal drehte sie sich um. Ich dachte, schade, jetzt verlasse sie das Bett und verschwinde - eine Art Revanche. Falsch! Sie zog nur das Nachthemd aus und rutschte näher zur Wand; ich lag links von ihr. Sie zupfte an der Bettdecke und zog sie hoch bis zu meinem Kinn.

- So! Jetzt frierst du nicht mehr.

Nach einer Weile gab ich meine starre Rückenlage auf und wandte mich zu ihr. Meine Hand ruhte auf ihren Brüsten. Hanni bewegte sich nicht, gab aber kleine Brummgeräusche von sich. So lagen wir etwa eine Viertelstunde ... möglicherweise waren es nur ein paar Minuten. Dann drehte ich mich wieder auf den Rücken. Sie legte ihre Hand auf meinen Bauch. Ich wagte kaum zu atmen, das leise Zittern kam jetzt wieder. Ihre Hand blieb nicht mehr lange ruhig, sie bewegte sich ein wenig. Es half mir allerdings kaum.

Nichts!

Ich verstand es nicht. Eine ziemlich neue Erfahrung, leider im dümmsten Augenblick. Und auch später: kein Wachstum, nicht die geringste Veränderung, wirklich - nichts.

Wie konnte das nur geschehen?, fragte ich mich. Die Kälte? Gut, die war schon vorher da gewesen. Oder die 
Überraschung? Oder das schlechte Gewissen, meine Schuldgefühle? Oder noch ganz andere Ablenkungen, die mir in dem Augenblick nicht bewusst waren?

Peinlich war mir das Ganze! Hanni kränken oder gar verletzen, nein, das wollte ich sicher nicht. Und ich dachte, über diese Entgleisung - besser: mein Versagen - mit ihr zu sprechen, wäre das Falscheste, was ich machen könnte. Das würde zu gar nichts führen.

Ich schwieg. Sie auch. Nur zwei, drei kurze Schluchzer hörte ich ... und dann - ich dachte, ich sei eingeschlafen und das gehöre zum Traum - und dann kamen ein paar Schnarchtöne, am Anfang leise, später etwas lauter. Ich hielt für einige Sekunden den Atem an ... war hellwach, irritiert, verwirrt; ich hatte eher beschwichtigende Bemerkungen von ihr erwartet oder, ja, auch das, ein stilles Weinen.

Gemischte Gefühle stiegen in mir hoch, sehr gemischt. Irgendwann schlief ich dann doch ein. Es war sicher spät. Ich erinnere mich jetzt, wie ein rötlicher Sonnenstrahl plötzlich eine Wandecke in Hannis Schlafzimmer erhellte.

Dr. med. Adolf Jens Koemeda

«Breitenstein"

CH-8272 Ermatingen

Tel. 0716641110
Etwa zwei Stunden später - Frühstück. Wir schwiegen, es gab aber trotzdem keine gespannte Stimmung im
Raum; vor allem keine Fragen, keine beruhigenden Worte oder Vorwürfe. Das wusste ich zu schätzen!

Nachdem ich ein dickes Schinkenbrot und zwei Portionen Rührei gegessen hatte, fuhr mir Hannelore durch das Haar.

- Schön, sagte sie, - schön, dass du da bist.

Ich schaute sie an, sagte aber nichts. Keine Ahnung, was in dem Augenblick die beste Entgegnung gewesen wäre.

Erst nach einer Pause: - Ich bin müde, Hanni. Ich glaube, ich muss noch einmal kurz ins Bett. Ich habe heute Nacht kaum ein Auge zugetan.

- Gute Idee! Vielleicht werde ich mich auch hinlegen. Zuerst aber die Küche.

Sie kam. Ich wusste nicht wann, ich war tatsächlich schnell eingeschlafen. Sie weckte mich: langsam, vorsichtig und sehr behutsam.

Es war ein schöner Samstagvormittag. Als sie aufstand und ihr Nachthemd anziehen wollte, reklamierte ich.

- Aber Simmi!, sagte sie. - Es ist bald zwölf. Ich sollte doch etwas für uns kochen.

Bildnachweis

() Photodesign | Dreamstime.com 